\title{
Densification behavior of hydroxyapatite green pellets prepared by different methods
}

\author{
Jae-Hyun KIM, Kazumichi YANAGISAWA, ${ }^{\dagger}$ Ayumu ONDA, Eri SASABE* and Tetsuya YAMAMOTO* \\ Research Laboratory of Hydrothermal Chemistry, Faculty of Science, Kochi University, Kochi 780_8520, Japan \\ * Department of Oral and Maxillofacial Surgery, Kochi Medical School, Kochi University, Nankoku 783-8505, Japan
}

The densification behavior of the green pellets with different densities prepared from hydroxyapatite powders consisting of plate-like particles was investigated. The green pellets were prepared by two methods, hydrothermal hot-pressing and uniaxial pressing, at different compression pressures. The hydrothermal hot-pressing gave the green pellets with densities higher than those using with uniaxial pressing. The shrinkage of the green pellets was observed by calcination at temperature above $800^{\circ} \mathrm{C}$. The green pellets with higher bulk density gave the sintered compacts with higher density. When the calcination temperature was increased, densification proceeded with the increase in pore diameter and the decrease of pore volume. Even at temperature below $700^{\circ} \mathrm{C}$, the size of pores increased with the increase in calcination temperature without shrinkage of the green pellets. Thus, the green compacts of the same density but with different pore sizes distribution prepared by hydrothermal hot-pressing and uniaxial pressing, had similar pore size distribution after calcination at $700^{\circ} \mathrm{C}$, As a result, they had the same densification behavior by calcination at high temperature above $800^{\circ} \mathrm{C}$. The densification behavior was found to be dependent on the density of green pellets, but not on the method of preparation of green pellets.

(C2015 The Ceramic Society of Japan. All rights reserved.

Key-words : Hydroxyapatite, Densification, Hydrothermal hot-pressing, Uniaxial pressing

[Received August 15, 2015; Accepted October 10, 2015]

\section{Introduction}

Hydroxyapatite $\left[\mathrm{Ca}_{10}\left(\mathrm{PO}_{4}\right)_{6}(\mathrm{OH})_{2}\right.$ : HAP] is one of the attractive biomaterials due to its similarity in properties of bone that includes chemical composition, biodegradability, bioactivity, and osteoconductivity. ${ }^{1-5)}$ Although HAP bioceramics have excellent properties as bioactive materials, they are not suitable for load bearing areas due to their low fracture strength. ${ }^{1-4), 6)-8)}$ Thus, HAP bioceramics are currently applied to repair of periodontal defects, tooth replacement, repair of large bone defects, ear and eye implants, and so on. ${ }^{1-4), 6), 9)}$ They are also used as scaffolds in tissue engineering for bone or dentin regeneration. ${ }^{1-4), 10), 11)}$

The main function of porous ceramic in body is to serve a substrate for proliferation and differentiation of cells seeded or infiltrated from the surrounding tissues followed by bone ingrowth into pores. ${ }^{15)}$ In particular, bone penetration in pores of implants is significantly affected by several factors, including porosity, pore size distribution, pore morphology, and interconnecting porosity. It is reported that pores with a diameter of 100350 microns are suitable for cell colonization and vascularization leading to bone penetration into the ceramics structure. ${ }^{4), 12)-14)}$ On the other hand, small-sized pores with nano- and micro- scale dimension affect the osteointegration process. It is because such pores are similar in size to those of proteins such as fibronectin, and the pores can promote protein adhesion to ceramic surface. ${ }^{12)}$ Therefore, plasma proteins and blood coagulation materials coat the implant before the osteogenic cell adhesion. ${ }^{12), 15)}$

Pores in HAP ceramics are usually introduced by calcination of HAP powders regardless of porogens. ${ }^{16)-18)}$ In other words, the understanding of the densification behavior of HAP powders is

\footnotetext{
Corresponding author: K. Yanagisawa; E-mail: yanagi@kochi-u. ac.jp
}

essential for the preparation of HAP bioceramics with pores. It is well known that the densification of powders depends on the properties of green pellets prepared by compaction of powders. The compacting method of HAP powders to prepare green pellets is very important for the preparation of HAP bioceramics. It is because the properties of green pellets significantly affect the density and mechanical strength of the resulted ceramics after sintering. HAP green pellets are normally prepared by uniaxial pressing, but it is usually difficult to get green pellets with density over $50 \%$. We have developed the hydrothermal hot-pressing method to prepare densified compacts by continuous compression of powders under hydrothermal conditions at low temperature. ${ }^{19)}$ In this technique, water acts as lubricant, and compression accelerates densification of powders. Furthermore, hydrothermal reaction results in bonding of powder particles to increase the mechanical strength of the compacts. The pores inside the compacts prepared by hydrothermal hot-pressing are usually open. It is because the space among the particles is filled with water which will be evaporated after hydrothermal hot-pressing. This technique has been used to prepare solidified compacts of various materials including $\mathrm{HAP}^{20)-24)}$

In this study, two different methods, uniaxial pressing and hydrothermal hot-pressing, were employed to prepare green pellets from HAP powders at different compression pressures. It was clarified that the hydrothermal hot-pressing technique accelerated the compaction and crystallization of the HAP powder. Nakahira et al. ${ }^{23}$ used hydrothermal hot-pressing to prepare HAP compacts and post-sintered these compacts at high temperature. They described that HAP samples post-sintered after hydrothermal hot-pressing treatment had a lower relative density and higher open porosity than those prepared by normal sintering. In this study, the densification behavior of the HAP green pellets prepared under different conditions was systematically inves- 
tigated by their calcination at high temperature to get fundamental information for preparation of HAP bioceramics. It is concluded that the density of the green pellets determined their densification behavior by sintering at high temperature, but not the method to prepare the green pellets.

\section{Experimental procedure}

The starting hydroxyapatite powder was commercially available (HAP-300, Taihei Chem. Ind. Co., Japan). Green pellets were prepared by two methods, hydrothermal hot-pressing (HHP) and uniaxial cold pressing (UCP), using the same apparatus. The starting HA powder $(3.0 \mathrm{~g})$ was kneaded with $10 \mathrm{wt} \%$ water, placed in a HHP cylindrical autoclave with an inner diameter of $2 \mathrm{~cm}$, and pressed uniaxially at 15 or $60 \mathrm{MPa}$. After keeping the pressure constant for $5 \mathrm{~min}$, the pellet was taken out from the autoclave. The pellets were referred to as CP15 and CP60, respectively. For the HHP treatment, the powder compressed at 15 or $60 \mathrm{MPa}$ in the autoclave was heated to $200^{\circ} \mathrm{C}$, and the temperature and pressure were kept constant for $2 \mathrm{~h}$. After the HHP treatment, the autoclave was cooled down to room temperature. The pellets prepared by HHP were referred to as HP15 and HP60, respectively. The pellets were heated at a rate of $10^{\circ} \mathrm{C} / \mathrm{min}$ to a sintering temperature up to $1300^{\circ} \mathrm{C}$ and the temperature was kept for $2 \mathrm{~h}$. The sintered compacts were referred to as CP15-, CP60-, HP15-, and HP60- with the sintering temperature. The green pellets and sintered compacts were characterized by bulk density determined from the weight and apparent volume of the compacts and apparent density measured by Archimedes' principle using water, microstructure of fracture surfaces observed by scanning electron microscopy (JEOL, JSM-6500-F), and open porosity and pore diameter distribution determined by mercury intrusion porosimetry (Micrometritics, AutoPore IV). The bulk density and apparent density were shown as relative density as against the real density of HAP $\left(3.16 \mathrm{~g} / \mathrm{cm}^{3}\right)$.

\section{Results and discussion}

\subsection{Properties of the green pellets.}

Figure 1 shows the SEM photograph of the starting HAP300. It consisted of plate-like particles with $1 \mu \mathrm{m}$ in size which aggregated to form a card house structure. The XRD diffraction pattern of HAP300 was exactly the same as that of CP60 (Fig. 3). The broad diffraction peaks except (002) diffraction indicate that HAP300 is low crystalline hydroxyapatite.

Table 1 shows the properties of the green pellets prepared under different conditions. When the compression pressure of the formation of green pellets was increased, their bulk density was increased. But their total intrusion volume up to the lowest measurement limit of $3 \mathrm{~nm}$ and average pore size were decreased.

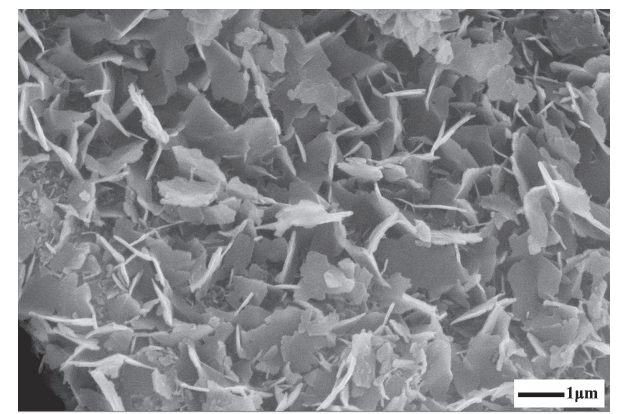

Fig. 1. SEM photograph of the starting hydroxyapatite powder (HAP300).
These results give the general conclusion that the compression accelerates the compaction of the starting powder. The hydrothermal hot-pressing technique gave the green pellets with higher density, in comparison with uniaxial pressing. As a result, the bulk density of HP15 prepared by hydrothermal hot-pressing at $15 \mathrm{MPa}$ was equal to that of CP60 prepared by uniaxial pressing at $60 \mathrm{MPa}$. HP60 prepared by hydrothermal hot-pressing at 60 MPa had a high bulk density over $60 \%$.

Figure 2 shows the cumulative intrusion volume against pore diameter of the green pellets. The compression of the starting powder at $60 \mathrm{MPa}$ decreased the amount of large pores in the green pellets. Similarly, the hydrothermal hot-pressing technique decreased the amount of large pores in the green pellets. It is noteworthy that the green pellets prepared by hydrothermal hot-pressing had no pores smaller than $10 \mathrm{~nm}$, while the pellets prepared by uniaxial pressing had pores smaller than $10 \mathrm{~nm}$. HP15 and CP60 had the same bulk density, but the total intrusion volume of HP15 $(0.4183 \mathrm{~mL} / \mathrm{g})$ was much larger than that of CP60 $(0.2677 \mathrm{~mL} / \mathrm{g})$. This difference suggests that CP60 must have a large amount of undetected pores smaller than $3 \mathrm{~nm}$ of the detection limit. Thus, the pore size distributions of HP15 and CP60 were very different, even though their bulk densities were the same.

\subsection{Densification behavior of the green pellets}

Figure 3 shows the XRD patterns of the green pellets of CP60 (a) and HP15 (b), and sintered compacts prepared from them. As mentioned previously, CP60 consisted of low crystalline hydroxyapatite. Its crystallinity was slightly increased with the increase in calcination temperature up to $700^{\circ} \mathrm{C}$, and remarkably increased at temperature above $800^{\circ} \mathrm{C}$. The crystallinity of HP15 was higher than that of CP60 due to the crystallization during the hydrothermal hot-pressing treatment, and was com-

Table 1. Properties of the green pellets

\begin{tabular}{ccccccc}
\hline & $\begin{array}{c}\text { Pressure } \\
(\mathrm{MPa})\end{array}$ & $\begin{array}{c}\text { Reaction } \\
\text { temperature. } \\
\left({ }^{\circ} \mathrm{C}\right)\end{array}$ & $\begin{array}{c}\text { Relative } \\
\text { bulk } \\
\text { density } \\
(\%)\end{array}$ & $\begin{array}{c}\text { Relative } \\
\text { apparent } \\
\text { density } \\
(\%)\end{array}$ & $\begin{array}{c}\text { Total } \\
\text { intrusion } \\
\text { volume } \\
(\mathrm{mL} / \mathrm{g})\end{array}$ & $\begin{array}{c}\text { Average } \\
\text { pore size } \\
(\mathrm{nm})\end{array}$ \\
\hline CP15 & 15 & 25 & 34.07 & 91.2 & 0.5369 & 23.4 \\
CP60 & 60 & 25 & 43.02 & 93.4 & 0.2677 & 14.1 \\
HP15 & 15 & 200 & 43.04 & 99.7 & 0.4183 & 32.1 \\
HP60 & 60 & 200 & 61.27 & 98.1 & 0.1530 & 13.2 \\
\hline
\end{tabular}

CP15 and CP60 were prepared by uniaxial cold pressing, and HP15 and HP60 by hydrothermal hot-pressing.

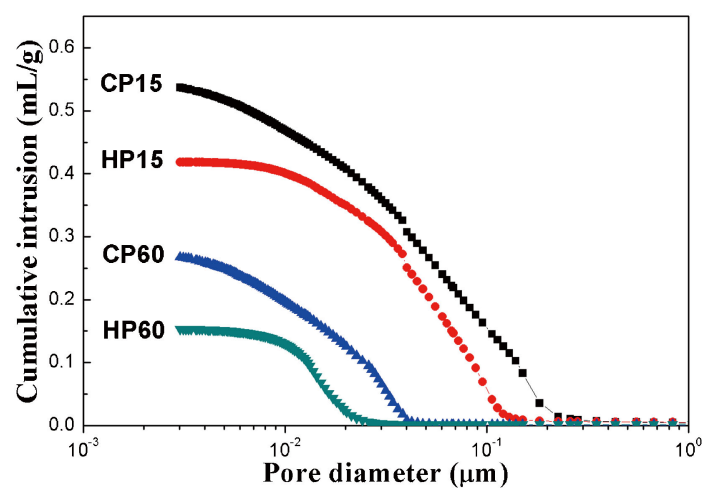

Fig. 2. Cumulative intrusion vs. pore size of the green pellets prepared by uniaxial pressing at $15 \mathrm{MPa}(\mathrm{CP} 15)$ and $60 \mathrm{MPa}(\mathrm{CP} 60)$ and by hydrothermal hot-pressing at $15 \mathrm{MPa}(\mathrm{HP} 15)$ and $60 \mathrm{MPa}(\mathrm{HP} 60)$ at $200^{\circ} \mathrm{C}$. 
parable to that of the compact of $\mathrm{CP} 60$ calcined at $700^{\circ} \mathrm{C}$. The crystallinity of HP15 was slightly increased by calcination at $400^{\circ} \mathrm{C}$. It unchanged by calcination from 400 to $700^{\circ} \mathrm{C}$, but was increased by calcination above $800^{\circ} \mathrm{C}$, in the same way of CP60. Similarly, the crystallinity of the sintered compacts prepared from CP15 and HP60 was increased remarkably by calcination at temperatures above $800^{\circ} \mathrm{C}$.

Figure 4 shows the bulk density of the green pellets and sintered compacts obtained at different calcination temperatures. The densities of all green pellets remained unchanged by calcination below $700^{\circ} \mathrm{C}$. The shrinkage of all green pellets started at $800^{\circ} \mathrm{C}$, and the densification proceeded with the increase in calcination temperature. The green pellets with higher bulk density
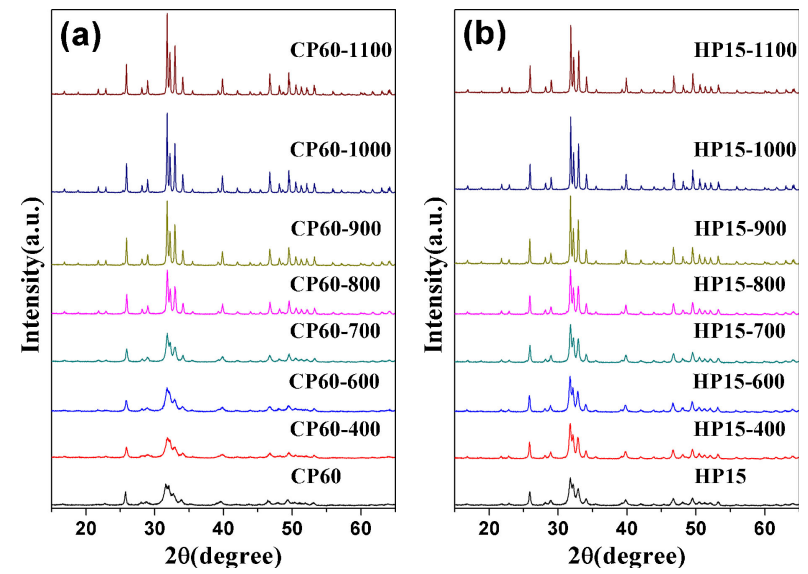

Fig. 3. XRD patterns of the green pellets and sintered compacts of (a) CP60 and (b) HP15.

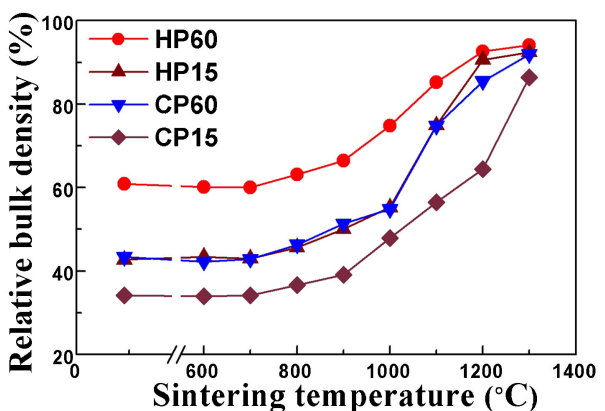

Fig. 4. Densification behavior of the green pellets prepared by uniaxial pressing at $15 \mathrm{MPa}(\mathrm{CP} 15)$ and $60 \mathrm{MPa}(\mathrm{CP} 60)$ and by hydrothermal hotpressing at $15 \mathrm{MPa}(\mathrm{HP} 15)$ and $60 \mathrm{MPa}(\mathrm{HP} 60)$ at $200^{\circ} \mathrm{C}$. gave the sintered compacts with higher density. The green pellets of CP60 and HP15 had the same bulk density of $43 \%$, and their densification behavior against the sintering temperature showed the same tendency. These results suggest that the densification process is heavily dependent on the density of the green pellets, regardless of the method of preparation of green pellets.

The compacts calcined at low temperature had high apparent densities in comparison with bulk densities, which suggests that most of the pores were open. The apparent density decreased after the shrinkage proceeded to form the compacts with bulk density beyond $80 \%$ (CP15-1300, CP60-1200, HP15-1200, HP60-1100). The decrease of the apparent density suggested the formation of closed pores. However, the apparent density was increased together with a slight increase in bulk density by calcination at higher temperature.

Figure 5 shows the pore diameter distribution of the green pellets and sintered compacts obtained by the calcination at different temperatures. A small volume of pores was detected by mercury intrusion porosimetry in the samples calcined above $1100^{\circ} \mathrm{C}$, except for $\mathrm{CP} 15$. When $\mathrm{CP} 15$ was calcined at $700^{\circ} \mathrm{C}$ (CP15-700), pores smaller than $0.02 \mu \mathrm{m}$ in diameter were decreased and pores of about $0.18 \mu \mathrm{m}$ in diameter were increased. Even when the calcination temperature was increased to $900^{\circ} \mathrm{C}$ (CP15-900), the same phenomenon was observed and the pore size was mainly $0.18 \mu \mathrm{m}$ in diameter. The temperature range of this process corresponded to the slow densification process of $\mathrm{CP} 15$ at temperature from 700 to $900^{\circ} \mathrm{C}$. At $1000^{\circ} \mathrm{C}(\mathrm{CP} 15-1000)$, the pore size was apparently increased, which corresponded to the first densification of $\mathrm{CP} 15$ at temperature above $1000^{\circ} \mathrm{C}$. With the increase in calcination temperature from 1000 to $1200^{\circ} \mathrm{C}$, the size of pore diameter was increased to $0.5 \mu \mathrm{m}$. When HP15 was calcined at $700^{\circ} \mathrm{C}$ (HP15-700), the amount of pores smaller than $0.03 \mu \mathrm{m}$ in diameter were decreased and that of pores of about $0.1 \mu \mathrm{m}$ in diameter were increased. When the calcination temperature was increased from 700 to $800^{\circ} \mathrm{C}$ (HP15-800), the size of pores was apparently increased. It was continuously increased with the increase in calcination temperature up to $1000^{\circ} \mathrm{C}$ (HP151000). CP60 did not contain pores larger than $0.03 \mu \mathrm{m}$, but the calcination at $700^{\circ} \mathrm{C}(\mathrm{CP} 60-700)$ produced larger pores with about $0.1 \mu \mathrm{m}$ in diameter and gave the same pore diameter distribution of HP15-700. The change of the pore diameter distribution of $\mathrm{CP} 60$ by further calcination at high temperature was the same as that for HP15, which was consistent with the similar densification behavior of CP60 and HP15. HP60 contained only pores smaller than $0.02 \mu \mathrm{m}$, but the pore size was increased from 0.025 to $0.055 \mu \mathrm{m}$ when $\mathrm{HP} 60$ was calcined at $700^{\circ} \mathrm{C}$. HP60-700 contained the pores with a homogeneous diameter in comparison with other compacts obtained by calcination at $700^{\circ} \mathrm{C}$. Further

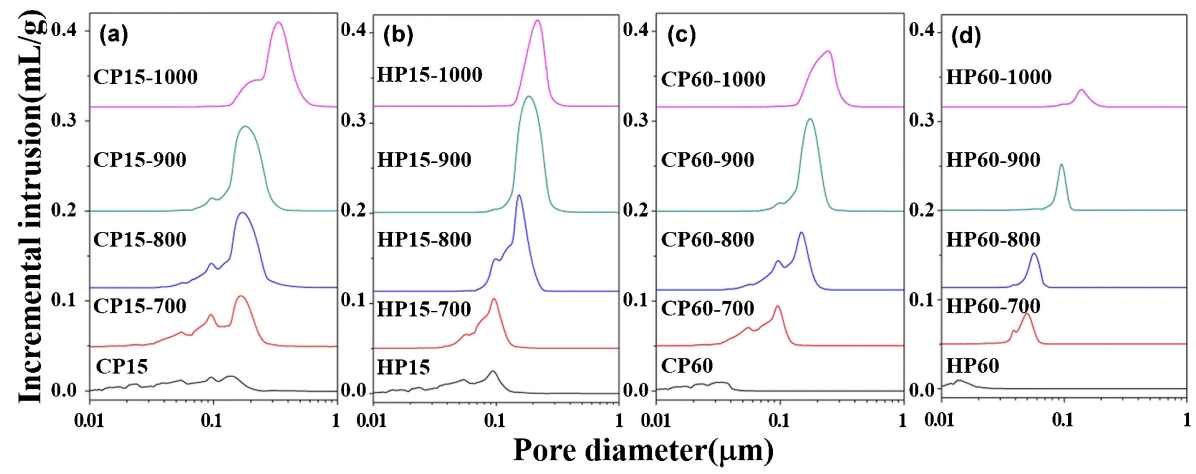

Fig. 5. Pore diameter distribution of the sintered compacts obtained from (a) CP15, (b) HP15, (c) CP60, and (d) HP60. 

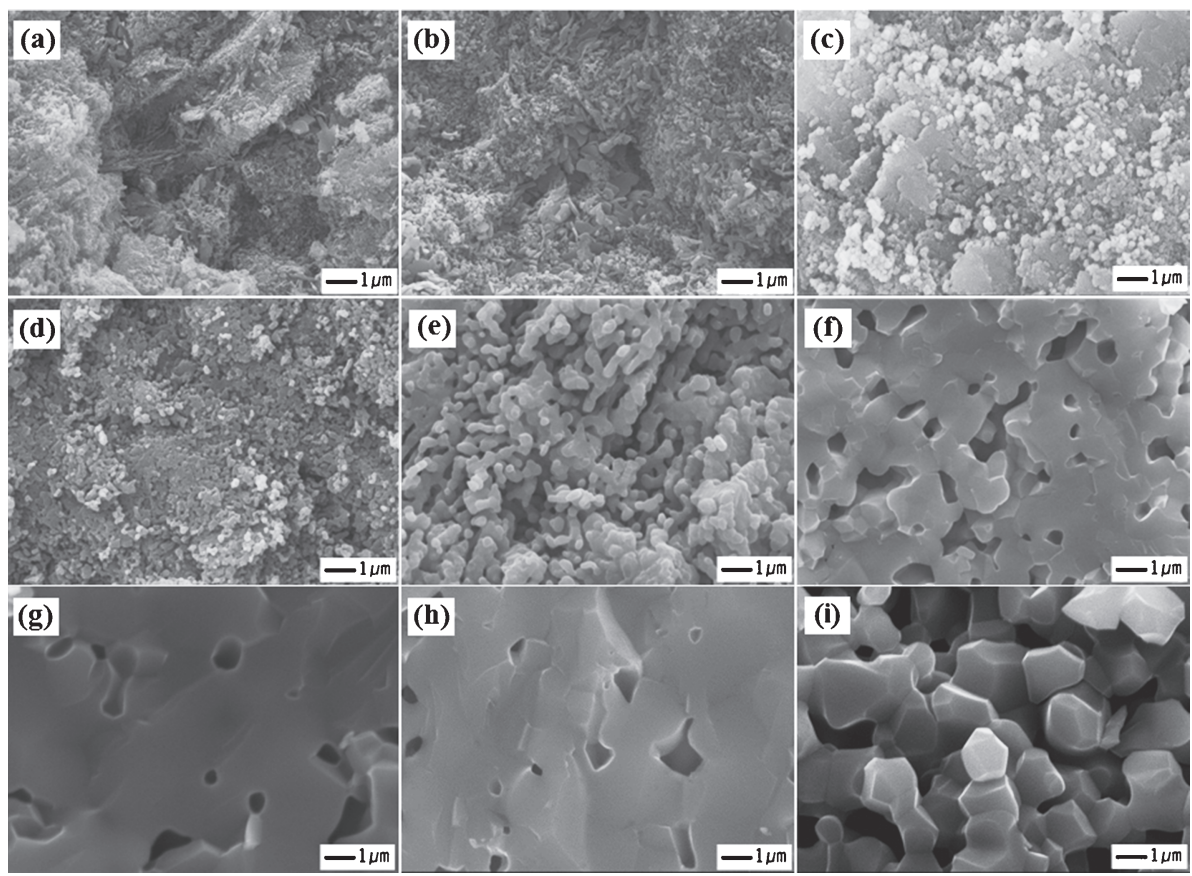

Fig. 6. Microstructures of fracture surfaces of (a) CP60-700, (b) HP15-700, (c) HP60-700, (d) CP60-800, (e) CP60-1000, (f) CP60-1100, (g) CP60-1200, (h) HP60-1200, and (i) CP15-1200.

calcination of HP60 at high temperature resulted in the increase in pore size and the decrease of pore volume.

It is reported that coarsening of continuous pore space during initial and intermediate sintering stages is caused by localized transport of atoms or molecules (diffusion or viscous flow) as well as by bulk particle movement (rearrangement). ${ }^{25}$ ) In this study, the increase in the pore size was observed without shrinkage of the green pellets by calcination at $700^{\circ} \mathrm{C}$. At the same time, the pore size distribution became homogeneous. The size depended on the bulk density of the green pellets and might be related to the solid and space volume ratio in the green pellets.

Figure 6 shows the fracture surfaces of the sintered compacts. CP60-700 [Fig. 6(a)] consisted of fine particles including platelike particles. HP15-700 [Fig. 6(b)] consisted of rounded particles which might be formed by the hydrothermal treatment. The fracture surface of HP60-700 [Fig. 6(c)] was different from those of CP60-700 and HP15-700. The original plate-like particles of HAP300 were completely destroyed and HP60-700 consisted of relatively large spherical particles of submicron order. The formation of large particles might explain why HP60-700 did not have pores smaller than $0.025 \mu \mathrm{m}$. When CP60 was calcined at $800^{\circ} \mathrm{C}$ [Fig. $6(\mathrm{~d})$ ], the constituent particles became rounded. Grain growth and neck formation were observed by the calcination of $\mathrm{CP} 60$ at $1000^{\circ} \mathrm{C}$ [Fig. 6(e)], and further grain growth was observed in CP60-1100 [Fig. 6(f)] and CP60-1200 [Fig. 6(g)] by the increase in calcination temperature. Fracture surfaces of the calcined compacts of HP15 at each temperature were similar to those of CP60. The calcination of $\mathrm{HP} 60$ at $1200^{\circ} \mathrm{C}$ also gave the well-sintered fracture surface [Fig. 6(h)], though the compacts of $\mathrm{CP} 15$ calcined at $1200^{\circ} \mathrm{C}$ [Fig. 6(i)] consisted of faceted grains with large pores. When $\mathrm{CP} 15$ was calcined at $1300^{\circ} \mathrm{C}$, further densification and grain growth were observed.

\section{Conclusions}

Hydroxyapatite green pellets were prepared from the commercially available chemical consisting of plate-like particles with $1 \mu \mathrm{m}$ in size by uniaxial pressing and hydrothermal hotpressing at different compression pressures. The hydrothermal hot-pressing significantly accelerated the compaction of powders to provide the pellets with higher density in comparison with the uniaxial pressing at the same compression pressure. The increase in pore size of the compacts without shrinkage was observed by the calcination of the green pellets at temperature below $700^{\circ} \mathrm{C}$. The shrinkage of all green pellets started to occur when the calcination temperature is above $800^{\circ} \mathrm{C}$. The green pellets with higher bulk density provided the sintered compacts with higher density. It was found that the green pellets of the same density prepared by uniaxial pressing and hydrothermal hot-pressing had the same densification behavior at high temperature. It is concluded that the densification behavior depended on the density of green pellets, but not on the method to prepare green pellets.

It was found that the sintered compacts with bulk density less than $80 \%$ had only open pores. The formation temperature of closed pores depended on the bulk density of the green pellets. Base on this study, we can design HAP porous materials consisting of open pores alone with controlled pore volume and pore diameter by selecting the bulk density of the green pellets and calcination temperature.

Acknowledgement The authors are thankful to Taihei Chem. Ind. Co., Japan, for offering HAP300. The authors acknowledge Dr Hon-Tung Wong for his proofreading of this manuscript.

\section{References}

1) R. Z. LeGeros, Chem. Rev, 108, 4742-4753 (2008).

2) M. Wang, Biomaterials, 24, 2133-2151 (2003).

3) R. Murugan and S. Ramakrishna, Compos. Sci. Technol., 65, 2385-2406 (2005).

4) T. Abdurrahim and I. Sopyan, Recent Patents Biomed. Eng. (N.Y.), 1, 213-229 (2008).

5) C. Loty, J. M. Sautier, H. Boulekbache, T. Kokubo, H. M. Kim and N. Forest, J. Biomed. Mater. Res., 49, $423-434$ (2000).

6) L. L. Hench, J. Am. Ceram. Soc., 74, 1487-1510 (1991). 
7) T. Li, J. Lee, T. Kobayashi and H. Aoki, J. Mater. Sci.: Mater. Med., 7, 355-357 (1996).

8) J. Weng, Q. Liu, J. G. C. Wolke, X. Zhang and K. de Groot, Biomaterials, 18, 1027-1035 (1997).

9) W. Suchanek and M. Yoshimura, J. Mater. Res., 13, 94-117 (1998).

10) L. D. Silverman, L. Lukashova, O. T. Herman, J. M. Lane and A. L. Boskey, J. Orthop. Res., 25, 23-29 (2007).

11) D. A. Wahl, E. Sachlos, C. Liu and J. T. Czernuszka, J. Mater. Sci.: Mater. Med., 18, 201-209 (2007).

12) V. S. Komlev and S. M. Barinov, J. Mater. Sci.: Mater. Med., 13, 295-299 (2002).

13) M. Yamamoto, Y. Tabata, H. Kawasaki and Y. Ikada, J. Mater. Sci.: Mater. Med., 11, 213-218 (2000).

14) J. J. Klawitter and S. F. Hulbert, J. Biomed. Mater. Res. Symp., 2, 161-229 (1971).

15) R. A. Smith, M. W. Mosesson, A. U. Daniels and T. K. Gartner, J. Mater. Sci.: Mater. Med., 11, 279-285 (2000).

16) E. Landi, A. Tampieri, G. Celotti and S. Sprio, J. Eur. Ceram.
Soc., 20, 2377-2387 (2000).

17) P. E. Wang and T. K. Chaki, J. Mater. Sci.: Mater. Med., 4, 150-158 (1993).

18) M. Figueiredo, A. Fernando, G. Martins, J. Freitas, F. Judas and H. Figueiredo, Ceram. Int., 36, 2383-2393 (2010).

19) N. Yamasaki, K. Yanagisawa, M. Nishioka and S. Kanahara, J. Mater. Sci. Lett., 5, 355-356 (1986).

20) N. Yamasaki, T. Kai, M. Nishioka, K. Yanagisawa and K. Ioku, J. Mater. Sci. Lett., 9, 1150-1151 (1990).

21) K. Ioku, K. Yamamoto, K. Yanagisawa and N. Yamasaki, Phosphorus Res. Bull., 4, 65-70 (1994).

22) K. Hosoi, T. Hashida, H. Takahashi, N. Yamasaki and K. Korenaga, J. Am. Ceram. Soc., 79, 2771-2774 (1996).

23) A. Nakahira, T. Murakami, T. Onoki, T. Hashida and K. Hosoi, J. Am. Ceram. Soc., 88, 1334-1336 (2005).

24) J. Li and T. Hashida, J. Mater. Sci., 42, 5013-5019 (2007).

25) H. E. Exner and C. Müller, J. Am. Ceram. Soc., 92, 1384-1390 (2009). 